\title{
Educational case series of electrocardiographs during the COVID-19 pandemic and the implications for therapy
}

Ching-Hui Sia ${ }^{1,2, *}$, MBBS, MRCP, Jinghao Nicholas ${\underline{\mathrm{Ngiam}^{3, *}}}^{,}, \mathrm{MBBS}, \mathrm{MRCP}$, Nicholas $\underline{\mathrm{Chew}}{ }^{3}$, MBBS, MRCP, Darius Lian Lian $\underline{B e h}^{4}$, MBBS, MRCP, Kian Keong $\underline{P_{0} h^{1,2}}$, MBBChir, FACC
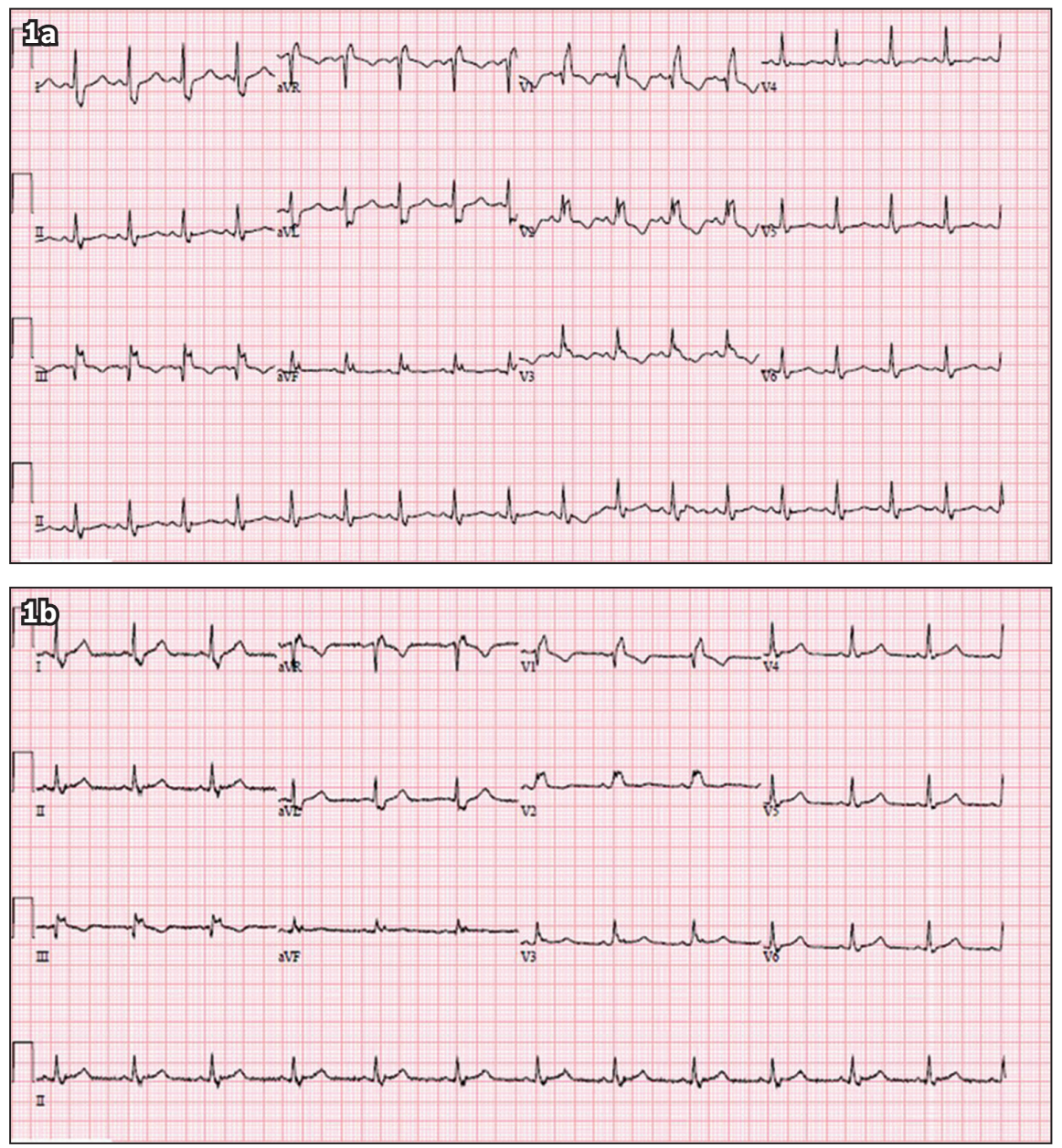

Fig. 1 Case 1: ECG at (a) presentation and (b) prior to discharge two weeks later.

\section{CASE 1}

\section{CLINICAL PRESENTATION}

A 37-year-old Malay woman with a history of hypertension, poorly controlled diabetes mellitus and polycystic ovarian syndrome presented with a one-week history of dry cough and rhinorrhoea. She had no family history of cardiac disease or sudden cardiac death. She was in close contact with a relative who had been recently diagnosed with coronavirus disease 2019 (COVID-19). On examination, her temperature was $37.0^{\circ} \mathrm{C}$, blood pressure $132 / 90 \mathrm{mmHg}$, heart rate 82 beats/minute, respiratory rate 20 breaths/minute and saturation $98 \%$ on room air. Physical examination revealed dual heart sounds and clear lungs. What does her electrocardiogram (ECG) at presentation (Fig. 1a) and prior to discharge two weeks later (Fig. 1b) show?

Her chest radiograph was normal and there was no cardiomegaly (Fig. 2). Laboratory investigations revealed a normal full blood count with no evidence of lymphopenia, and C-reactive protein, lactate dehydrogenase and ferritin levels were not elevated. Her creatinine level was normal, and there were no electrolyte derangements. The patient was managed with three days of oral lopinavir/ritonavir, but this medication was stopped due to gastrointestinal side effects.

${ }^{1}$ Department of Cardiology, National University Heart Centre Singapore, ${ }^{2}$ Yong Loo Lin School of Medicine, National University of Singapore, ${ }^{3}$ University Medicine Cluster, ${ }^{4}$ Division of Infectious Disease, University Medicine Cluster, National University Health System, Singapore

*These two authors contributed equally as first author in this work.

Correspondence: Dr Ching Hui Sia, Senior Resident, Department of Cardiology, National University Heart Centre Singapore, 1E Kent Ridge Road, NUHS Tower Block Level 9 , Singapore 119228. ching_hui_sia@nuhs.edu.sg 


\section{ECG INTERPRETATION}

Both the ECGs at presentation (Fig. 1a) and discharge (Fig. 1b) show normal sinus rhythm with a right bundle branch block. The initial ECG shows a prolonged corrected QT interval of 555 $\mathrm{ms}$, while the ECG prior to discharge shows that the corrected QT interval had returned to $470 \mathrm{~ms}$ (by Bazett's formula). The derivation of the corrected QT interval is shown in Fig. 3.

\section{CLINICAL COURSE}

The patient was admitted to the general ward for monitoring. Her nasopharyngeal swab confirmed the diagnosis of COVID-19. Her QT interval was prolonged prior to the administration of any medications. The patient was treated with oral lopinavir/ritonavir, which did not prolong the QT interval further. However, the medication was stopped due to gastrointestinal side effects. She was not switched to hydroxychloroquine because of the prolonged QT interval. Nevertheless, the patient improved clinically and did not require intensive care. She did not experience any lethal

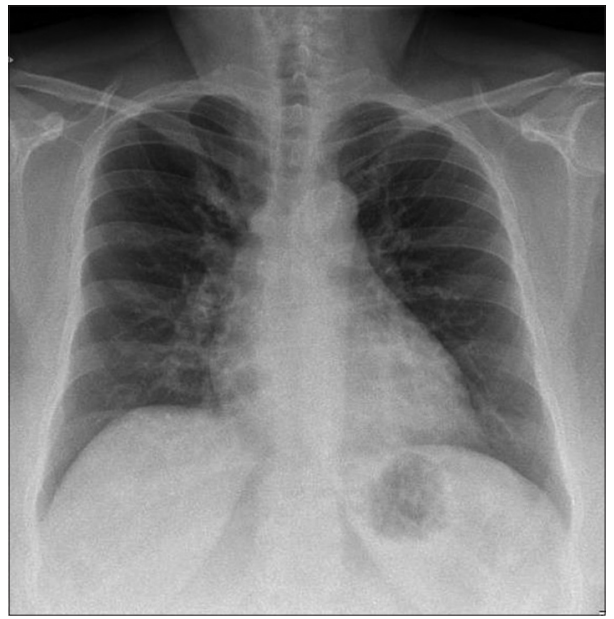

Fig. 2 Case 1: Chest radiograph at presentation. arrhythmias or palpitations while hospitalised. She recovered with no complications and tested negative for COVID-19 on two consecutive nasopharyngeal swabs. She was discharged after one month.

\section{CASE 2}

\section{CLINICAL PRESENTATION}

A 79-year-old Chinese man with a background of hypertension, hyperlipidaemia and ischaemic heart disease presented with a two-week history of dry cough and intermittent fever. He had undergone a coronary artery bypass graft surgery ten years ago. He had been regularly taking clopidogrel, simvastatin, bisoprolol, amlodipine and enalapril $2.5 \mathrm{mg}$ every morning. He had no known history of atrial fibrillation and denied any chest pain, palpitation or shortness of breath on exertion. He did not have any positive contact with COVID-19 cases or travel history. On examination, his temperature was $37.2^{\circ} \mathrm{C}$, blood pressure $112 / 61 \mathrm{mmHg}$, heart rate 84 beats/minute, respiratory rate 20 breaths/minute and saturation $100 \%$ on room air. Physical examination revealed dual heart sounds and crepitations in the right lung base. His laboratory findings were unremarkable apart from hyponatraemia (serum sodium $127 \mathrm{mmol} / \mathrm{L}$; normal: 135-145 mmol/L) and lymphopenia (absolute lymphocyte count $0.53 \times 10^{9} / \mathrm{L}$; normal: $\left.0.91-3.52 \times 10^{9} / \mathrm{L}\right)$. His renal function, liver function, C-reactive protein level and ferritin level were normal. His chest radiograph showed right lower zone infiltrates (Fig. 4). The rest of the lungs were clear. His COVID-19 test was positive. What does the ECG show (Fig. 5)?

\section{ECG INTERPRETATION}

ECG shows an irregularly irregular rhythm at 60-70 beats/ minute with a fibrillatory baseline. There is an incomplete right bundle branch block. The ST segment is normal, and there is no evidence of significant QT interval prolongation (corrected QT

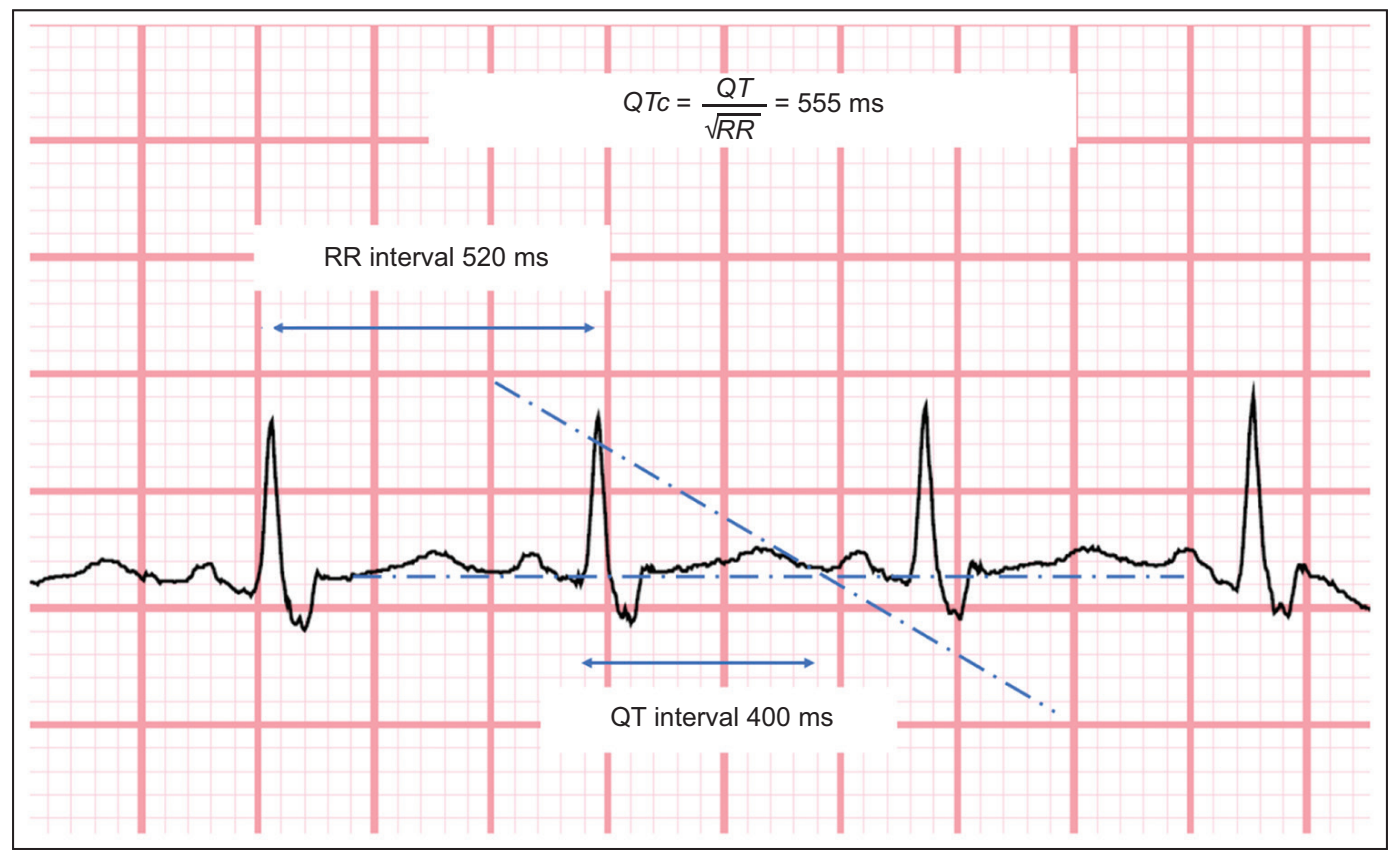

Fig. 3 Figure shows calculation of the corrected QT interval (Bazett's formula) 
interval [QTc] $414 \mathrm{~ms})$. These findings are consistent with atrial fibrillation.

\section{CLINICAL COURSE}

The patient was admitted to the general ward and his nasopharyngeal swab confirmed the diagnosis of COVID-19. He was given symptomatic relief for his upper respiratory tract symptoms. He remained afebrile in the ward and did not develop any exertional dyspnoea or desaturation. He did not require any antiviral therapy. His sodium levels returned to normal and lymphopenia improved on repeat testing. His calculated $\mathrm{CHA}_{2} \mathrm{DS}_{2}$-VASc score was 3. He was started on anticoagulation with a direct oral anticoagulant, apixaban. He recovered well and was subsequently discharged to a community care facility after two weeks.

\section{CASE 3}

\section{CLINICAL PRESENTATION}

A 65-year-old Indian man with a background of hypertension presented with a one-week history of dry cough and rhinorrhoea. He had no family history of cardiac disease or sudden cardiac

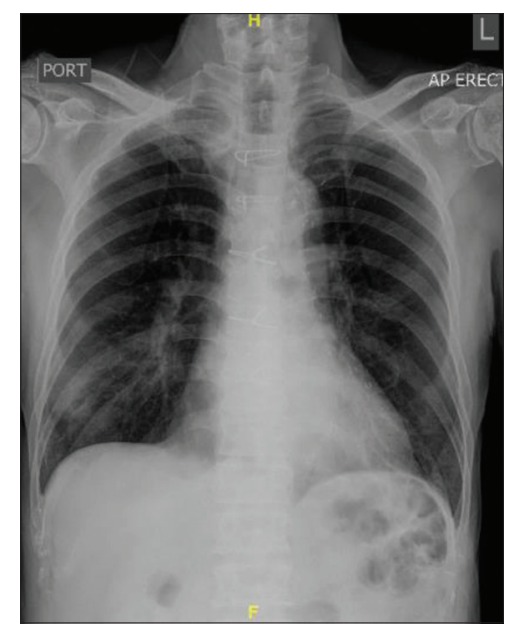

Fig. 4 Case 2: Chest radiograph shows right lower zone infiltrates and the absence of cardiomegaly. death. He was in close contact with a relative who had been recently diagnosed with COVID-19. On examination, his temperature was $38.4^{\circ} \mathrm{C}$, blood pressure $117 / 74 \mathrm{mmHg}$, heart rate 102 beats/minute, respiratory rate 20 breaths/minute and saturation $95 \%$ on room air. Physical examination revealed dual heart sounds and bilateral crepitations. His initial chest radiograph showed right middle and lower zone infiltrates (Fig. 6a). Laboratory investigations revealed a normal full blood count with no evidence of lymphopenia and normal renal function. C-reactive protein was elevated at $90 \mathrm{mg} / \mathrm{dL}$ (normal: 0-10 mg/dL), while lactate dehydrogenase was $921 \mathrm{U} / \mathrm{L}$ (normal: 250-580 U/L) and serum ferritin level was 950 \%g/L (normal: 20$300 \mu \mathrm{g} / \mathrm{L}$ ). His nasopharyngeal swab confirmed the diagnosis of COVID-19. The patient subsequently deteriorated with increasing shortness of breath and oxygen requirements. He was transferred to the intensive care unit (ICU) and intubated for mechanical ventilation. Repeat chest radiograph showed worsening bilateral infiltrates (Fig. 6b). The patient was treated with oral lopinavir/ ritonavir for five days and interferon beta- $1 \mathrm{~b}$ for three days. On Day 3 of the ICU stay, the patient turned hypotensive. Troponin I level rose from $20.1 \mathrm{ng} / \mathrm{L}$ to $85.0 \mathrm{ng} / \mathrm{L}$ (normal: 0-17.4 ng/L). His ECG at presentation (Fig. 7a) and during the hypotensive episode in the ICU are shown (Fig. 7b). What do the ECGs show?

\section{ECG INTERPRETATION}

The initial ECG (Fig. 7a) shows a normal sinus rhythm at a heart rate of 95 beats/minute. The subsequent ECG (Fig. 7b) shows the sinus rhythm deteriorating into an accelerated idioventricular rhythm of approximately 100 beats/minute. There were no discernible $p$ waves in the latter half of the ECG, with a widened QRS complex.

\section{CLINICAL COURSE}

Within the next few hours, the patient collapsed and went into episodes of pulseless ventricular tachycardia requiring cardiopulmonary resuscitation and defibrillation. After return of spontaneous circulation, he was started on an amiodarone infusion. Transthoracic echocardiography demonstrated

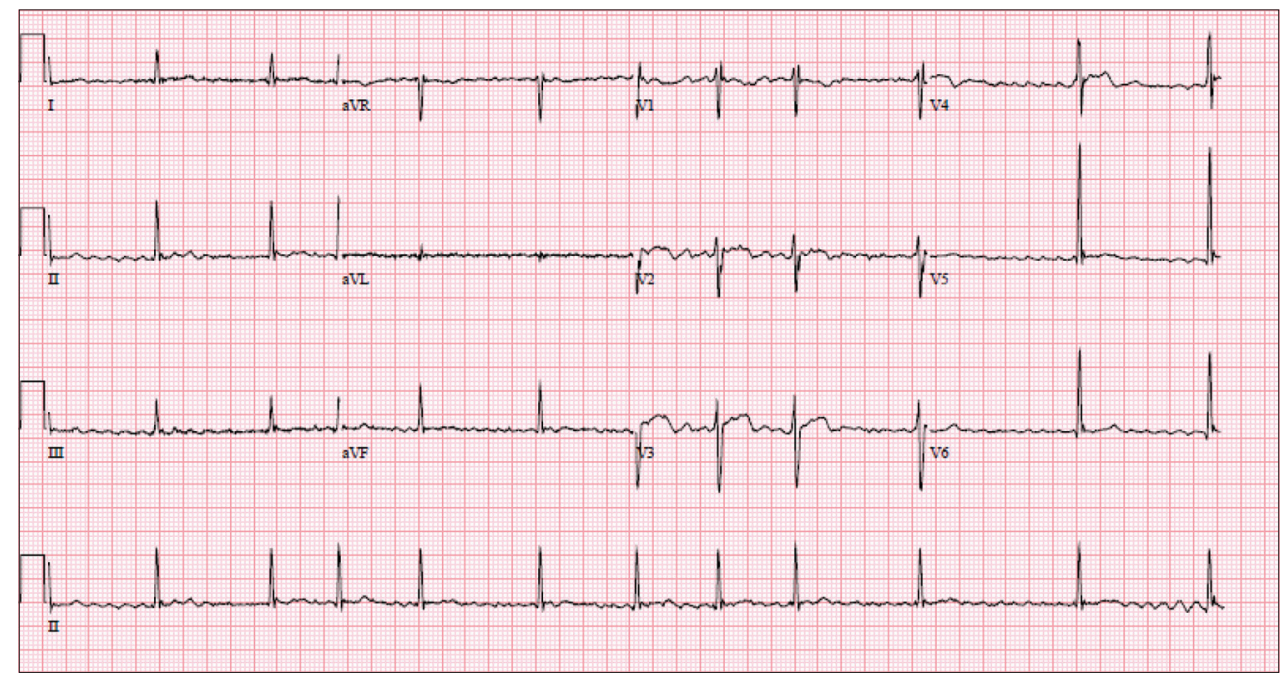

Fig. 5 Case 2: ECG at presentation. 

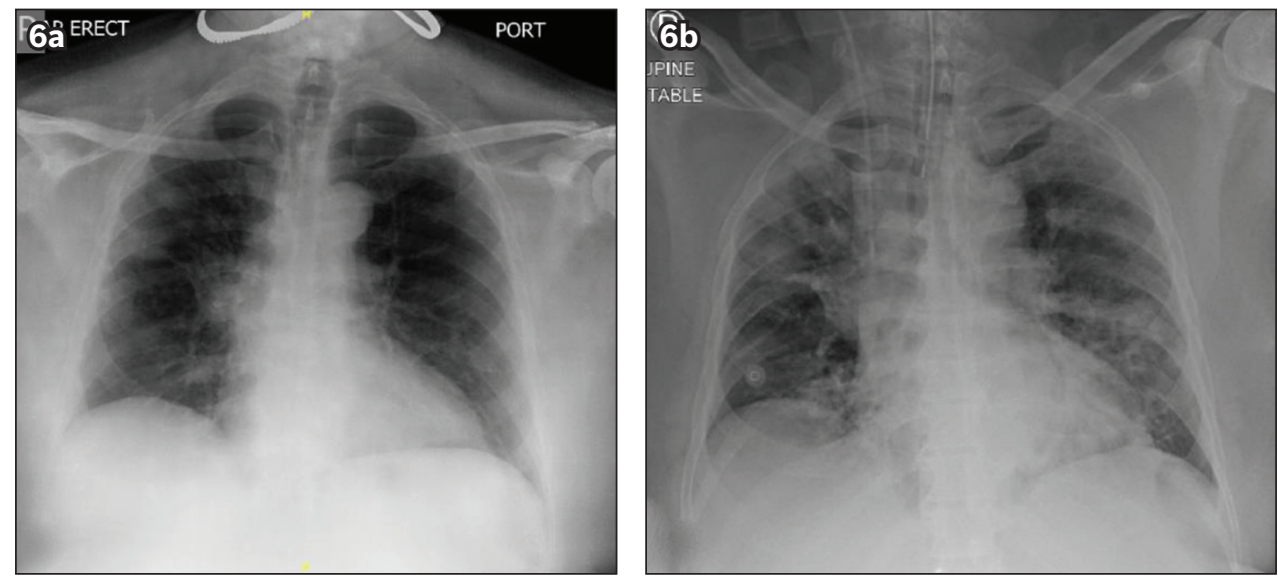

Fig. 6 Case 3: Chest radiograph (a) at presentation and (b) after intubation.
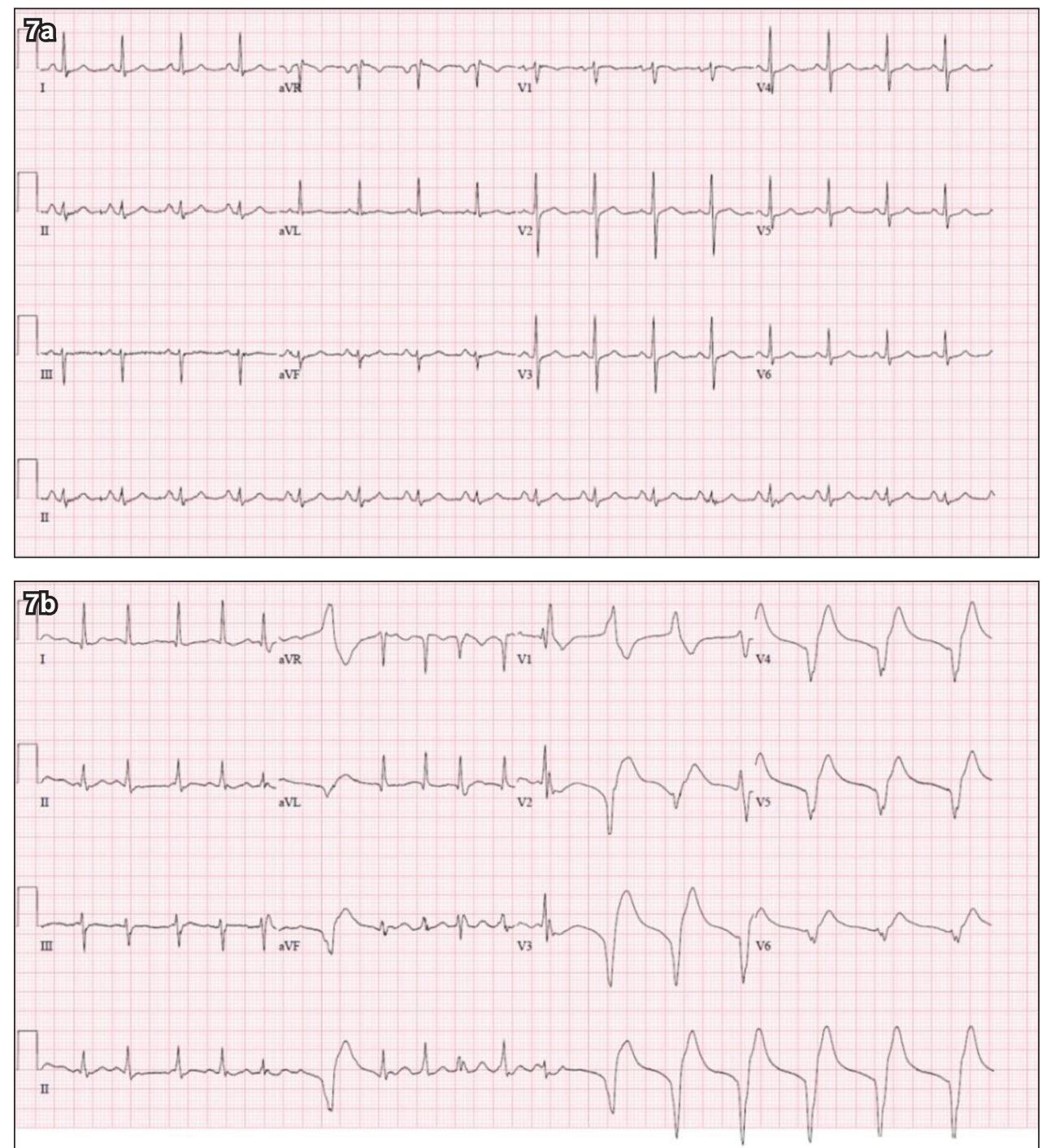

Fig. 7 Case 3: ECG at (a) presentation and (b) during hypotensive episode in the intensive care unit.

preserved left ventricular ejection fraction (55\%), with normal chamber sizes and no regional wall motion abnormalities. He continued to improve clinically and was extubated after one week in the ICU. He had two consecutive nasopharyngeal swabs that tested negative for COVID-19 and was discharged from hospital after six weeks.

\section{DISCUSSION}

COVID-19 is an infection caused by the severe acute respiratory syndrome coronavirus 2 (SARS-CoV-2), which was first described at the end of 2019. The first known cases were from a cluster of viral pneumonia in Wuhan, Hubei province, China. ${ }^{(1)}$ Electrocardiographic manifestations at presentation are highly 
variable. Frequently, the ECG may reveal normal sinus rhythm with no significant abnormalities. In patients with existing heart disease, it is possible that COVID-19 may behave in a similar way to other acute systemic illness and precipitate common atrial arrhythmias. In patients with more severe cardiac involvement of COVID-19, more severe arrhythmias may be seen.

Other common electrocardiographic manifestations, in the form of cardiac and conduction system disease, have also been described in patients with COVID-19. This was in addition to other more direct cardiac manifestations such as acute coronary syndrome, myocarditis and heart failure. ${ }^{(2)}$ These patients tend to be more severely ill, requiring intensive care and mechanical ventilation. Life-threatening arrhythmias may then present as cardiac involvement of the disease, or an overwhelming systemic inflammatory response induced by COVID-19 (as in Case 3).

The prevalence of arrhythmias and disease of the conduction system may be as high as $44 \%$ of patients in the intensive care unit and $17 \%$ of patients in the general cohort, ${ }^{(3)}$ based on a singlecentre study of 138 patients in Wuhan. Furthermore, it has been reported that $7.3 \%$ of patients presented with palpitations as part of their initial cluster of symptoms. ${ }^{(4)}$ In patients that were more severely ill, the presence of acute arrhythmias and conduction system disease may have been attributed to hypoxia and the presence of electrolyte derangements. However, the aetiology that determines whether patients with COVID-19 may present with arrhythmias early in their disease or with mild disease remains to be elucidated. ${ }^{(5)}$

Patients with COVID-19 commonly present with fever and acute respiratory symptoms, such as cough, rhinorrhoea, sputum production and shortness of breath. ${ }^{(4)}$ Indeed, most patients did not have symptoms of arrhythmias at presentation. Although palpitations were not an uncommon feature, it was rarely the dominant symptom reported by patients. ${ }^{(2)}$

\section{Common electrocardiographic manifestations of COVID-19}

There is no known electrocardiographic feature that is unique to COVID-19. The different electrocardiographic manifestations may be attributable to underlying acute infection or related to the unmasking of underlying cardiac disorders. The underlying mechanisms from which these electrocardiographic changes develop may remain unclear. Nevertheless, understanding the patient's ECG would have important implications for therapy.

\section{Sinus tachycardia}

Sinus tachycardia is the most common manifestation in patients with COVID-19. This may be seen in an inflammatory response or a response to fever. Patients who are acutely ill may also be volume depleted due to poor oral intake, and sinus tachycardia may be an expected compensatory response. Other rarer but potentially causative mechanisms for the development of sinus tachycardia include more sinister events such as myocarditis and pulmonary embolism. ${ }^{(6-8)}$

\section{Prolonged QTC}

A large New York study $(n=4,250)$ demonstrated that prolonged QTC $>500$ ms was seen in $6.1 \%$ of patients at presentation. ${ }^{(9)}$ The patient's baseline QT interval may thus affect the choice of antiviral therapy used in COVID-19 (as in Case 1). Therefore, measuring the QT interval at baseline is clinically important, as patients may have been started on medications such as hydroxychloroquine and azithromycin as therapy for COVID-19. ${ }^{(10)}$ These medications place patients at further risk of QTc prolongation and, consequently, lethal arrhythmias. Anti-retroviral medications such as boosted protease inhibitors (lopinavir and ritonavir) may also be associated with a possible risk of QTc prolongation, but the incidence of this is low. ${ }^{(11,12)}$ To our knowledge, there have not been any reports of QTC prolongation with intravenous remdesivir, an experimental therapy for COVID-19. Furthermore, in critically ill patients, significant electrolyte derangements such as hypokalaemia may also contribute to prolongation of the QT interval. ${ }^{(13)}$

\section{Atrial arrhythmias}

Common atrial arrhythmias such as atrial fibrillation and atrial flutter have been reported in COVID-19 patients. We presented a case of new-onset atrial fibrillation in association with COVID-19 in an elderly male patient (Case 2). The development of atrial fibrillation in our patient may be due to his underlying hypertension and history of ischaemic heart disease, which was precipitated by the acute illness. Although Case 2 did not require mechanical ventilation, mechanically ventilated COVID-19 patients were found to have a nearly ten-fold higher prevalence of atrial arrhythmias compared to those who did not require ventilation. ${ }^{(14)}$

\section{Unmasking underlying channelopathies}

It has been reported that underlying Brugada syndrome and its characteristic electrocardiographic findings may be unmasked in the acute setting by COVID-19 infection. ${ }^{(15)}$ Patients with underlying cardiac channelopathies such as Brugada syndrome and long QT syndrome may present with classic electrocardiographic changes in the context of acute febrile illness. ${ }^{(16)}$

\section{Bradycardias}

Bradycardias have not typically been reported in patients with COVID-19. However, severe bradycardia requiring pacemaker insertion was seen in up to $15 \%$ of patients with Middle East respiratory syndrome, another type of coronavirus. ${ }^{(17)}$ Bradycardia has also been reported in patients with coronaviruses that cause the common cold, although this is usually seen in paediatric settings. ${ }^{(18,19)}$

\section{Management considerations}

Because of the risk of COVID-19 patients developing arrhythmias, conduction systemic disease and myocardial injury, all patients should receive a baseline ECG at presentation. This would allow for a recording of the patient's QTC duration and baseline 
QRS-T morphology. If the patient's condition deteriorates during the course of disease, repeat ECG testing may reveal dynamic changes, such as those that reflect myocardial injury.

Furthermore, patients on therapy may also need to have their ECG QTc intervals monitored to minimise the risk of lethal ventricular arrhythmias. Medications such as hydroxychloroquine may prolong a patient's ECG QT interval by blocking the activity of potassium channels in the heart. ${ }^{(20)}$ These effects are similar to other medications such as quinidine and chloroquine. It is important to recognise that hydroxychloroquine is metabolised by cytochrome P450 3A4 in the liver, and hence liver enzyme inhibitors could raise plasma levels of these medications and lead to cardiac toxicity. ${ }^{(21)}$

Despite these concerns, hydroxychloroquine has rarely been demonstrated to cause lethal arrhythmias such as Torsades de pointes (TdP). This drug has been used widely in rheumatology conditions and as an antimalarial, and was found to be relatively safe. ${ }^{(22)}$ Hydroxychloroquine (with or without azithromycin) is often given for short durations (typically up to five days), which further lowers the risk of $\mathrm{TdP}$ in this population. In patients with COVID-19 who were on mechanical ventilation and treated with azithromycin and either high- or low-dose chloroquine, a higher proportion of patients with QTc prolongation (> $500 \mathrm{~ms}$ ) was reported in the high-dose group (18.9\% vs. $11.1 \%$ ), although this difference did not reach statistical significance. ${ }^{(23)}$ Two patients in the high-dose group experienced ventricular tachycardia, but no patient had TdP. The risk of QTc prolongation is lower with boosted protease inhibitors such as lopinavir and ritonavir, and it has not been reported in patients treated with intravenous remdesivir.

\section{CONCLUSION}

Electrocardiographic manifestations of COVID-19 are highly variable and nonspecific. This paper illustrated three cases with different electrocardiographic features of COVID-19 and the subsequent implications for therapy. Other possible arrhythmias and conduction abnormalities were also discussed. In our institution, baseline ECGs are obtained at admission for all COVID-19 patients. Practitioners should take note of the electrocardiographic manifestations of COVID-19, as they may affect therapy and prognosis.

\section{REFERENCES}

1. World Health Organization. WHO Director-General's remarks at the media briefing on 2019-nCoV on 11 February 2020. Available at: https://www.who. int/dg/speeches/detail/who-director-general-s-remarks-at-the-media-briefingon-2019-ncov-on-11-february-2020. Accessed 30 April 2020.

2. Driggin E, Madhavan MV, Bikdeli B, et al. Cardiovascular considerations for patients, health care workers, and health systems during the coronavirus disease 2019 (COVID-19) pandemic. J Am Coll Cardiol 2020; 75:2352-71.

3. Liu K, Fang YY, Deng Y, et al. Clinical characteristics of novel coronavirus cases in tertiary hospitals in Hubei Province. Chin Med J (Engl) 2020; 133:1025-31.

4. Wang D, Hu B, Hu C, et al. Clinical characteristics of 138 hospitalized patients with 2019 novel coronavirus-infected pneumonia in Wuhan, China. JAMA 2020; 323:1061-9.

5. Lakkireddy DR, Chung MK, Gopinathannair R, et al. Guidance for cardiac electrophysiology during the coronavirus (COVID-19) pandemic from the Heart Rhythm Society COVID-19 Task Force; Electrophysiology Section of the American College of Cardiology; and the Electrocardiography and Arrhythmias Committee of the Council on Clinical Cardiology, American Heart Association. Heart Rhythm 2020 Apr 1. https://doi.org/10.1016/j.hrthm.2020.03.028. [Epub ahead of print]

6. Poissy J, Goutay J, Caplan M, et al. Pulmonary embolism in COVID-19 patients: awareness of an increased prevalence. Circulation 2020; 142:184-6.

7. Inciardi RM, Lupi L, Zaccone G, et al. Cardiac involvement in a patient with coronavirus disease 2019 (COVID-19). JAMA Cardiol 2020; 5:1-6.

8. Cherian R, Poh KK. At the 'heart' of the COVID-19 outbreak: early cardiac implications and mitigating strategies. Singapore Med J 2020; 61:373-4.

9. Richardson S, Hirsch JS, Narasimhan M, et al. Presenting characteristics, comorbidities, and outcomes among 5700 patients hospitalized with COVID-19 in the New York City area. JAMA 2020; 323:2052-9.

10. Yao X, Ye F, Zhang M, et al. In vitro antiviral activity and projection of optimized dosing design of hydroxychloroquine for the treatment of severe acute respiratory syndrome coronavirus 2 (SARS-CoV-2). Clin Infect Dis 2020; 71:732-9.

11. Soliman EZ, Lundgren JD, Roediger MP, et al. Boosted protease inhibitors and the electrocardiographic measures of QT and PR durations. AIDS 2011;25:36777.

12. Roden DM, Harrington RA, Poppas A, Russo AM. Considerations for drug interactions on QTc in exploratory COVID-19 treatment. J Am Coll Cardiol 2020; 75:2623-4

13. Vandael E, Vandenberk B, Vandenberghe J, Willems R, Foulon V. Risk factors for QTc-prolongation: systematic review of the evidence. Int J Clin Pharm 2017; 39:16-25.

14. Goyal P, Choi JJ, Pinheiro LC, et al. Clinical characteristics of Covid-19 in New York City. N Engl J Med 2020; 382:2372-4.

15. Chang D, Saleh M, Garcia-Bengo Y, et al. COVID-19 infection unmasking Brugada syndrome. HeartRhythm Case Rep 2020; 6:237-40.

16. Amin AS, Klemens CA, Verkerk AO, et al. Fever-triggered ventricular arrhythmias in Brugada syndrome and type 2 long-QT syndrome. Neth Heart J 2010; 18:165-9

17. Saad M, Omrani AS, Baig K, et al. Clinical aspects and outcomes of 70 patients with Middle East Respiratory Syndrome coronavirus infection: a single-center experience in Saudi Arabia. Int J Infect Dis 2014; 29:301-6.

18. Sizun J, Soupre D, Giroux JD, et al. Nasal colonization with coronavirus and apnea of the premature newborn. Acta Paediatr 1993; 82:238.

19. Sizun J, Soupre D, Legrand MC, et al. Neonatal nosocomial respiratory infection with coronavirus: a prospective study in a neonatal intensive care unit. Acta Paediatr 1995; 84:617-20.

20. Wu Cl, Postema PG, Arbelo E, et al. SARS-CoV-2, COVID-19, and inherited arrhythmia syndromes. Heart Rhythm 2020; S1547-5271(20)30285-X.

21. Ambhore A, Teo SG, Bin Omar AR, Poh KK. Importance of QT interval in clinical practice. Singapore Med J 2014; 55:607-12.

22. Haeusler IL, Chan XHS, Guérin PJ, White NJ. The arrhythmogenic cardiotoxicity of the quinoline and structurally related antimalarial drugs: a systematic review. BMC Med 2018; 16:200.

23. Borba MGS, Val FFA, Sampaio VS, et al. Effect of high vs low doses of chloroquine diphosphate as adjunctive therapy for patients hospitalized with severe acute respiratory syndrome coronavirus 2 (SARS-CoV-2) infection: a randomized clinical trial. JAMA Netw Open 2020; 3:e208857. 


\section{SINGAPORE MEDICAL COUNCIL CATEGORY 3B CME PROGRAMME} (Code SMJ 202008B)

Question 1. The following statements regarding symptoms of coronavirus disease 2019 (COVID-19) are true:

(a) Cough in COVID-19 is always productive.

(b) Shortness of breath is a common presenting symptom.

(c) Rhinorrhoea is not seen in these patients.

(d) Patients may present with palpitations.

Question 2. The following statements regarding the presentation of COVID-19 are true:

(a) In COVID-19 pneumonia, patients always present with low oxygen saturation $\left(\mathrm{SpO}_{2}<95 \%\right)$.

(b) The most common electrocardiographic abnormality in patients with COVID-19 is sinus bradycardia.

(c) The initial chest radiograph may be normal.

(d) Patients may be afebrile at presentation.

Question 3. Cardiovascular manifestations of COVID-19 may include:

(a) Acute myocardial infarction.

(b) Myocarditis.

(c) Cardiac arrhythmias.

(d) Aortic dissection.

Question 4. Possible electrocardiographic manifestations of COVID-19 may include:

(a) Sinus tachycardia.

(b) Atrial fibrillation/flutter.

(c) Sinus bradycardia.

(d) Prolonged QT interval.

Question 5. Medications used in the therapy of COVID-19 that may cause prolonged QT interval include:
(a) Hydroxychloroquine.
(b) Azithromycin.
(c) Lopinavir/ritonavir.
(d) Remdesivir.

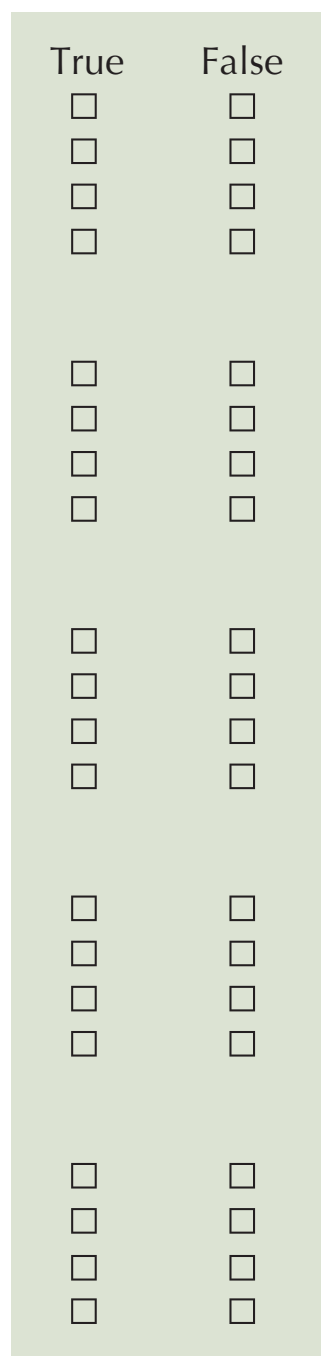

\section{Doctor's particulars:}

Name in full:

Specialty:

MCR no.:

Email:

\section{SUBMISSION INSTRUCTIONS}

Visit the SMI website: http://www.smj.org.sg/current-issue and select the appropriate quiz. You will be redirected to the SMA login page.

For SMA member: (1) Log in with your username and password (if you do not know your password, please click on 'Forgot your password?'). (2) Select your answers for each quiz and click 'Submit'.

For non-SMA member: (1) Create an SMJ CME account, or log in with your SMJ CME username and password (for returning users). (2) Make payment of SGD 21.40 (inclusive of $7 \%$ GST) via PayPal to access this month's quizzes. (3) Select your answers for each quiz and click 'Submit'.

RESULTS:

(1) Answers will be published online in the SMJ October 2020 issue. (2) The MCR numbers of successful candidates will be posted online at the SMJ website by 9 October 2020. (3) Passing mark is $60 \%$. No mark will be deducted for incorrect answers. (4) The SMJ editorial office will submit the list of successful candidates to the Singapore Medical Council. (5) One CME point is awarded for successful candidates. (6) SMC credits CME points according to the month of publication of the CME article (i.e. points awarded for a quiz published in the August 2020 issue will be credited for the month of August 2020, even if the deadline is in October 2020).

Deadline for submission (August 2020 SMJ 3B CME programme): 12 noon, 2 October 2020. 